\title{
Theoretical and practical aspects of the production of powdered semi-finished product from cultivated mushrooms pleurotus ostreatus
}

\author{
Nina Myachikova ${ }^{1,}{ }^{*}$, Alexey Remnev ${ }^{1}$, Yuri Boltenko ${ }^{1}$, Irina Korotkyh $^{1}$, Olga Binkovskaya $^{1}$, and Irina Zinoveva ${ }^{1}$ \\ ${ }^{1}$ Institute of Pharmacy, Chemistry and Biology, Belgorod State National Research University, Belgorod, Russia
}

\begin{abstract}
The substantiation of the technology of powdered semi-finished product from cultured mushrooms Pleurotus ostreatus is presented. The composition of volatile substances of fresh mushrooms Pleurotus ostreatus was studied. It was ascertained that these substances can bind by starch polysaccharides. The results of the conducted study showed that the best flavor-forming substances are preserved in the sample containing $8 \%$ of potato starch to the mass of mushrooms boiled in their own juice. Starch is recommended to insert in dry form at the temperature of mushrooms $45^{\circ} \mathrm{C}$.
\end{abstract}

\section{Introduction}

Features of the chemical composition, morphological structure, and technological properties of Pleurotus ostreatus require new approaches to their technological processing. Traditional technologies for processing this type of mushrooms are quite laborious process, because it is impossible to mechanize the machining operations. In this regard, the technology of production of powdered semi-finished products is proposed, the main prescription components are mushrooms Pleurotus ostreatus and potato starch. The development of such products will solve the problem of production of fast food.

Pleurotus ostreatus mushrooms have a faint aroma. It is also known [1], that at the product temperature of 60 ${ }^{\circ} \mathrm{C}$ and above, evaporating from the material, moisture carries away volatile components (up to $45 \%$ ). Due to the loss of volatile components, products lose their taste and aroma. Therefore, in order to preserve the taste and aroma substances available in mushrooms to the maximum properties: the higher the molecular weight of volatiles is, the less their diffusion in the polysaccharide matrix, the less their volatility and the stronger their binding.

\section{Experimental}

The object of the study was the technology of powdered semi-finished product from Pleurotus ostreatus mushrooms.

Vacuum drying was performed in the vacuum drying Cabinet SNVS-45. The pressure in the drying chamber was $50 \mathrm{~mm}$ of mercury, and the temperature was $60^{\circ} \mathrm{C}$.

Determination of moisture content. During the drying process, the humidity value of the material $\mathrm{W}^{0}$ cannot be used, since the mass of the material is continuously decreasing, which will introduce uncertainty in the characteristics of the drying process. The mass of absolutely dry material Mc remains unchanged during

*Corresponding author: myachikova@,bsu.edu.ru extent, it is advisable to introduce a corrective additive into the formulation of the product being developed, which contributes to their retention.

Research by a number of authors [2], allowed us to establish that native starches can be used as such additives. The advantages of using them are that they, on the one hand, are inert food materials, on the other, they have amorphous areas in their structure of starch grains. The presence of these sites is a necessary factor for the binding of volatiles. This was confirmed by studies of the mechanism of binding of organic compounds by polysaccharides in model experiments. Among the revealed regularities in the binding of volatile substances, one of the most important places is occupied by the conformation of polysaccharides. It was found that the amorphous state of the polymer matrix is the most effective polysaccharide state for holding volatiles [3]. In addition, the effectiveness of retention of volatiles depends on their structure and drying, so the concept of moisture content is introduced [4].

At certain intervals, a decrease in the mass of the product was determined during the drying process and its moisture content $(\%)$ was calculated using the formula:

$$
W^{c}=\frac{100 W}{M_{c}}
$$

where

$W^{c}$ - the moisture content of the product, \%;

$M_{c}$ - mass of absolutely dry substance, $\mathrm{g}$;

$W$ - mass of moisture in the product, g, which was calculated using the formula:

where

$$
W=M-M_{c}
$$

$M$ - product weight, $\mathrm{g}$.

Based on the results obtained, drying curves were constructed [4].

The content of aroma-forming substances was determined by gas chromatographic method using the 
chromato-mass spectrophotometer «Agilent Technologies», which includes a gas chromatograph 6890 , a mass-selective detector $5973 \mathrm{~N}$ with a library of mass spectra for 130,000 connections, and a device for static vapor-phase introduction of the sample 7694 HS [5].

\section{Results and discussion}

In the manufacture of powdered semi-finished product, the main ingredients are mushrooms Pleurotus ostreatus and potato starch, the concentration of which is selected based on maximum preservation of the taste and aroma substances of mushrooms, and prospective range of products manufactured on the basis of powdered semifinished product. The advantages of using products in dried form are due to the possibility of providing a wide range of products, the speed and simplicity of their preparation, and high bulk density during storage. The advantages of dried products also include the convenience of their storage, which does not require special conditions and a large amount of space.

The study of the composition of volatile substances of fresh mushrooms Pleurotus ostreatus (Fig. 1) showed that the main volatile flavor-forming substances are aliphatic alcohols and ketones with the number of carbon atoms $\mathrm{C}_{6}-\mathrm{C}_{8}$, namely: 1-hexanol, 3-heptanol, 3-octanol, 3-octane, 1-octene. The listed components have a small molecular weight; therefore, they are characterized by significant volatility. In addition, they are polar compounds that are found [1] to be better bound by amylopectin than by amylose.

When choosing the type of starch, the following factors were taken into account:

- availability of sufficient amylopectin;

- functional and technological properties (viscosity, turbidity);

- availability and cheapness.

Based on this, potato starch was used, which has 78$81 \%$ amylopectin in its composition; it has a significant viscosity, and also forms a transparent colorless paste.

Also, the previously conducted studies [2] revealed that potato starch is able to bind organic substances from aqueous solutions by $77.6 \%$, and only $16.3 \%$ of the substances are adsorbed on the surface, and the remaining $83.7 \%$ are bound inside the pores of the granules due to capillary forces and hydrophobic interactions with polysaccharides that are part of the starch. This has a significant impact on the persistence of volatile substances, since the compounds on the surface of starch will easily volatilize, oxidize, and be subjected by photodegradation.

The feasibility of using this type of starch is confirmed by the studies of other authors [6], who claim that potato starch is the best source of granulated starch microcapsules. As a result of the gradual swelling of starch granules in water or aqueous salt solutions, the amount of leaching material increases. Water penetrates into the inner area of the pellet through a channel to the eyehole.

The swelling presses the amorphous layer of material inside the granule [7] to its surface. The study of deepfrozen wet starch [8] showed that amylopectin rather than amylose is located on the surface. Therefore, it can be assumed that leaching of amylose occurs. With an increase in the amount of leaching (passing into solution) amylose in the granules, the volume of empty areas increases. Potentially, such empty areas can act as traps of substances that should be closed in microcapsules [9].

On the other hand, amylose fractions of starch will participate in the formation of so-called inclusion complexes, including those with polar molecules. The study of model compounds showed that the formed complexes can be either amorphous or crystalline [10].

In the production of dried products, the main process in the technological process of the production is drying, which largely determines the quality of the finished product.

The ongoing and final result of drying are largely determined by the operations that the material to be dried undergoes at the pre-treatment stage. Therefore, in order to eventually get a product with the specified quality indicators, it is necessary to consider the production process as a single, interconnected system consisting of parts whose interaction determines the quality just inherent to this system.

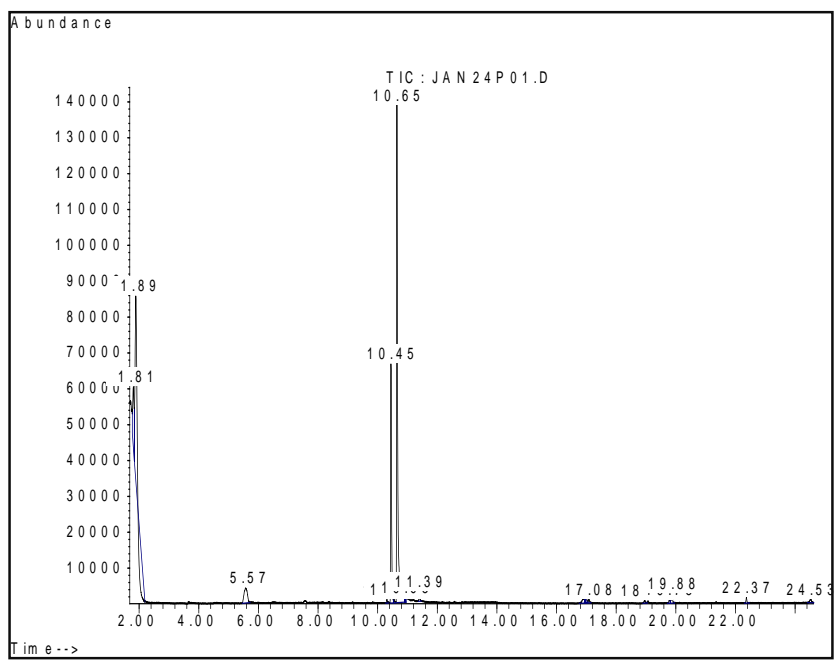

Fig. 1. Chromatogram of volatile compounds of fresh cultivated mushrooms Pleurotus ostreatus: 5.57: 1-Octene, 2Octene (E)- 2-Octene; 10.45: 3-Octanone, Butane, 1-[(2methyl-2-propenyl, 3-Heptanone, 5-methyl; 10.65: 3-Octanol, 3-Heptanol, 6-methyl; 11.39: 1-Hexanol, 2-ethil-2-Propil-1pentanol, 1-pentanol, 2-ethil-4-methil

In order to reduce the drying time, as well as to maximize the destruction of the tissue structure, which will ensure the transfer of low-molecular flavoring substances to the environment and more complete contact with starch polysaccharides, it is necessary to grind mushrooms. When grinding, the integrity of cells is disrupted, and, consequently, the access of enzymes to organic substances is facilitated. The study of the influence of temperature on the activity of proteolytic, redox enzymes and respiratory rate, and, consequently, on the speed of biochemical processes shows that temperature is a decisive factor. Thus, increasing the temperature of fruit bodies from 20 to $40{ }^{\circ} \mathrm{C}$ increases the activity of various enzymes by $1.5 \ldots 4$ times [11]. It was revealed that even after drying at a coolant temperature of $75{ }^{\circ} \mathrm{C}$, the dried product retains some activity of ascorbic oxidase, polyphenol oxidase, and probably other enzymes. Taking into account, the drying process should be carried out at a temperature of no 
more than $60^{\circ} \mathrm{C}$, i.e. favorable conditions for the action of enzymes will be created, it is necessary to provide conditions that promote inactivation of the enzyme systems. For this purpose, the developed technology provides for the process of adding mushrooms in their own juice.

In addition to inactivating enzymes, there are a number of other processes that also play a positive role:

- denaturation of proteins leads to the increase of their digestibility;

- reduction of microbial semination contributes to the increase of storage duration. According to available data [1], most products that have been pre-heat treated are better preserved;

- partial removal of moisture allows to further reduce the drying time [12].

Prepared in this way, the mushrooms are combined with starch and dried. In the technology of production of powdered semi-finished products from mushrooms, drying is the main stage of the technological process. Properly organized drying should ensure the fastest drying of the raw product to the required humidity, maximum preservation of taste, aroma, color of the raw material, as well as resistance to storage. A semi-finished product was subjected to drying, which was obtained by mixing mushrooms boiled in their own juice with starch. At the same time, the influence of factors such as:

- starch concentration;

- mixing temperature;

- method of inputting starch.

Based on this, the following samples were used as study objects (table 1).

At the first stage of the study, the influence of starch concentration, method of injection administration and mixing temperature on the duration of vacuum drying was studied.

Table 1. Characteristics of the studied samples

\begin{tabular}{|c|c|c|c|}
\hline $\begin{array}{c}\text { № of } \\
\text { sample }\end{array}$ & $\begin{array}{c}\text { Starch } \\
\text { concentration } \\
\mathbf{\%} \text { by weight } \\
\text { of boiled } \\
\text { mushrooms }\end{array}$ & $\begin{array}{c}\text { Method of } \\
\text { injection of } \\
\text { starch }\end{array}$ & $\begin{array}{c}\text { Mixing } \\
\text { temperatur } \\
\text { e, }{ }^{\circ} \mathbf{C}\end{array}$ \\
\hline $\mathbf{1}$ & 5 & In dry form & 45 \\
\hline $\mathbf{2}$ & 5 & In dry form & 65 \\
\hline $\mathbf{3}$ & 8 & In dry form & 45 \\
\hline $\mathbf{4}$ & 8 & In dry form & 65 \\
\hline $\mathbf{5}$ & 15 & In dry form & 45 \\
\hline $\mathbf{6}$ & 15 & In dry form & 65 \\
\hline $\mathbf{7}$ & 8 & $\begin{array}{c}\text { In suspension } \\
\text { form }\end{array}$ & 45 \\
\hline
\end{tabular}

The obtained dependences of the moisture content of the material on the drying time for different samples (according to table 1) are shown in Fig. 2-3.

Analysis of the obtained curves allows us to conclude that with increasing of starch concentration in the semifinished product, the drying time increases. This is obviously due to an increase in the amount of bound water, the destruction of which requires additional energy costs.

The temperature of starch mixing with mushrooms also has a significant effect on the duration of drying, which is also evidenced by the drying curves. At the temperature of mixing $45{ }^{\circ} \mathrm{C}$ (at different concentrations of starch) drying lasts $(14 \pm 1) \times 60^{2} \mathrm{~s}$, at a temperature of $65{ }^{\circ} \mathrm{C}-(16 \pm 1) \times 60^{2} \mathrm{~s}$. Obviously, this significant difference in duration is due to the fact that at $45^{\circ} \mathrm{C}$ only partial swelling of starch grains occurs, and, as a result, water is easily removed during the drying process. At $65^{\circ} \mathrm{C}$, partial gelatinization of starch grains occurs, which more firmly retain water, which leads to additional energy costs necessary for breaking the connections, and, consequently, to an increase in the drying time.

As it is shown by the conducted studies, the duration of drying largely depends on the method of injection of starch (in dry form or as a suspension (Fig. 4)).

When starch is injected as a suspension, the initial moisture content of the product increases, so it is necessary to spend more energy on breaking the connections between the starch grains and water and removing moisture from the product.

Thus, to reduce the drying time, it is advisable to combine starch with mushrooms during mixing at a temperature of $45{ }^{\circ} \mathrm{C}$ at the minimum feasible starch concentrations. It is revealed that the concentration of starch affects the retention of flavoring substances, as well as the functional and technological properties of the semi-finished product in the process of its further use in the composition of culinary products

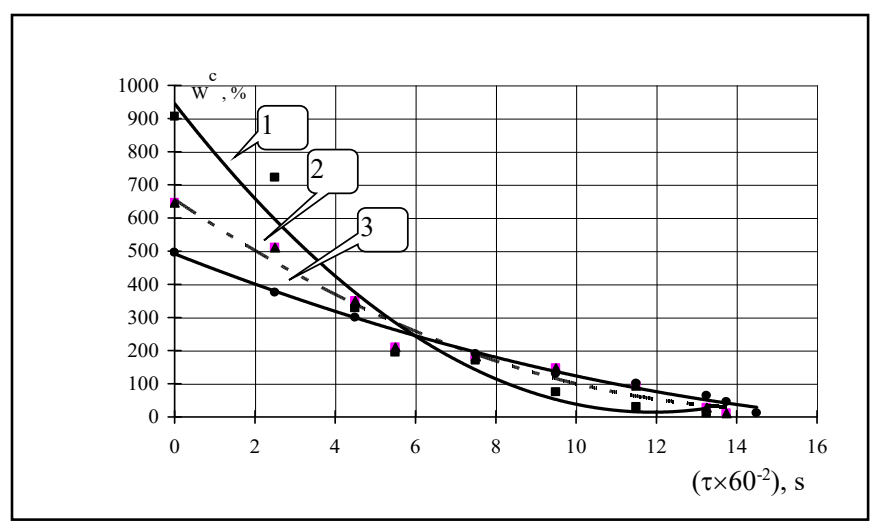

Fig. 2. Kinetics of vacuum drying of powdered semi-finished product from mushrooms at starch concentration: $1-5 \%, 2-$ $8 \%, 3-15 \%$ (mixing temperature $45{ }^{\circ} \mathrm{C}$ )

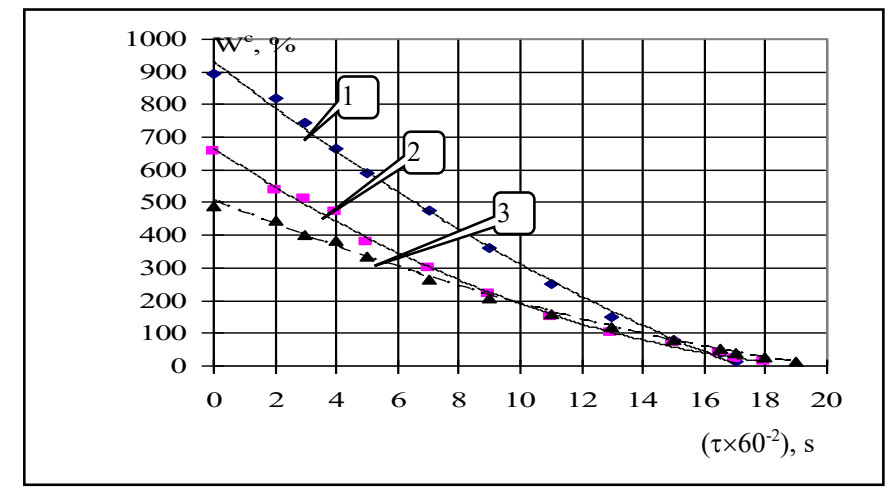

Fig. 3. Kinetics of vacuum drying of powdered semi-finished product from mushrooms at starch concentration: $1-5 \%, 2-$ $8 \%, 3-15 \%$ (mixing temperature $65^{\circ} \mathrm{C}$ ) 


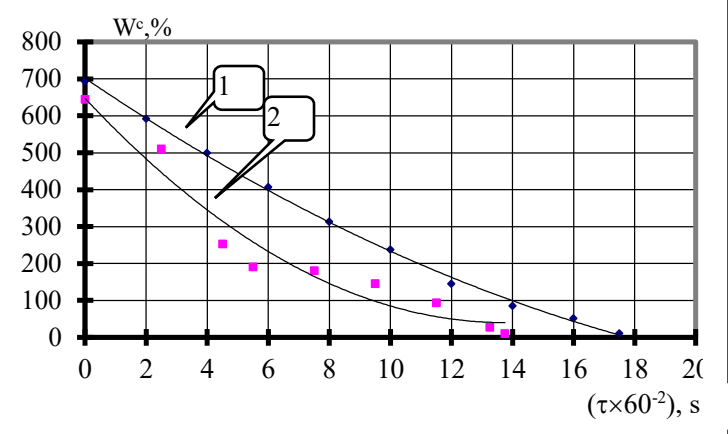

Fig. 4. Kinetics of vacuum drying of powdered semi-finished product from mushrooms when starch is injectied: 1-in dry form, 2-in suspension (mixing temperature $45^{\circ} \mathrm{C}$ )

In order to determine the effect of starch concentration on the retention of flavoring substances, gas chromatographic studies of allocated volatile substances from dry powder immediately after manufacture and after storage for 12 months were conducted. For study, 3 samples were used, preparing by the same technology, but having different amounts of starch in their composition: $0 ; 5$ and $8 \%$ by weight of the poached mushrooms. The results of experimental studies of freshly prepared samples (Fig. 5, 6, 7) show that the most volatile flavoring substances are released in a sample that does not contain starch and the least-in a sample containing $8 \%$ starch. A sample containing 5\% starch occupies an intermediate position. This suggests that with increasing of starch concentration in the system, more volatile flavoring substances are retained on the polysaccharide fractions of starch, respectively, less of them are lost.

It can be assumed that in the process of hydrothermal processing of semi-finished products, leading to starch gelatinization, which is accompanied by change in the structure of starch polysaccharides, there is a destruction of the connections between the starch polysaccharides and the taste and aroma substances held by them. As a result of the release of taste and aroma substances from the "bonds" of starch, their release into the environment occurs and, thus, the flavor of the finished product is created, which is very close to the aroma of fresh mushrooms.

Analyzing the chromatograms of samples stored for 12 months (Fig. 8, 9, 10), it can be noted that after long term storage, the maximum release of volatile substances is observed in the sample containing $8 \%$ starch, and the minimum-in the sample that does not contain starch. In other words, there is the direct relationship between the starch content and the preservation of volatile flavoring substances in the powdered semi-finished product from mushrooms during storage. Organoleptic evaluation of samples prepared on the basis of a powdered semifinished product from mushrooms with different concentrations of starch and having a viscosity corresponding to the viscosity of mushroom sauces prepared using traditional technology was carried out. As a result, it was revealed that the best sample is $8 \%$ starch to the mass of boiled mushrooms. These data are consistent with the results of chromatographic studies.

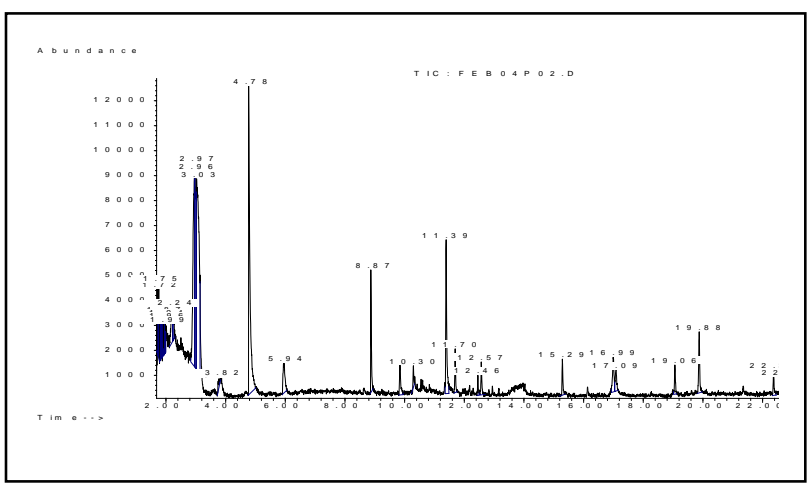

Fig. 5. Chromatogram of volatile compounds of a freshly prepared semi-finished mushroom powder containing no starch

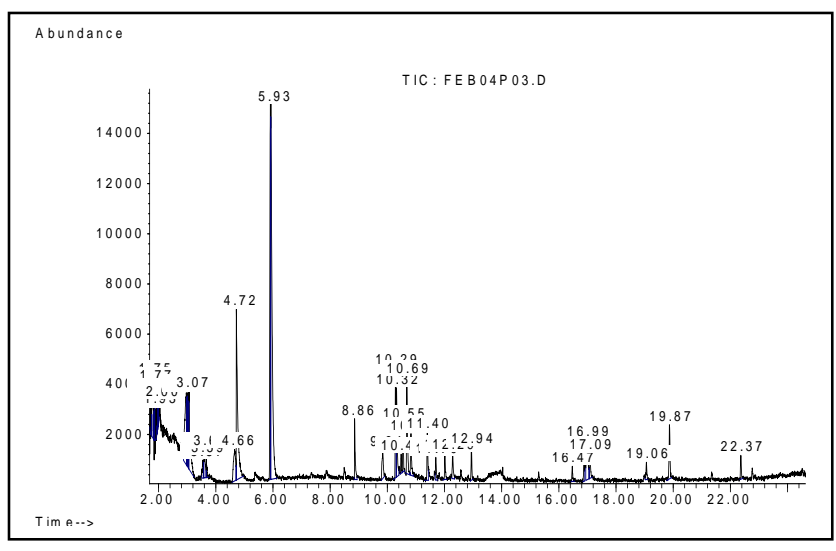

Fig. 6. Chromatogram of volatile compounds of a freshly prepared powdered semi-finished product from mushrooms containing $5 \%$ starch

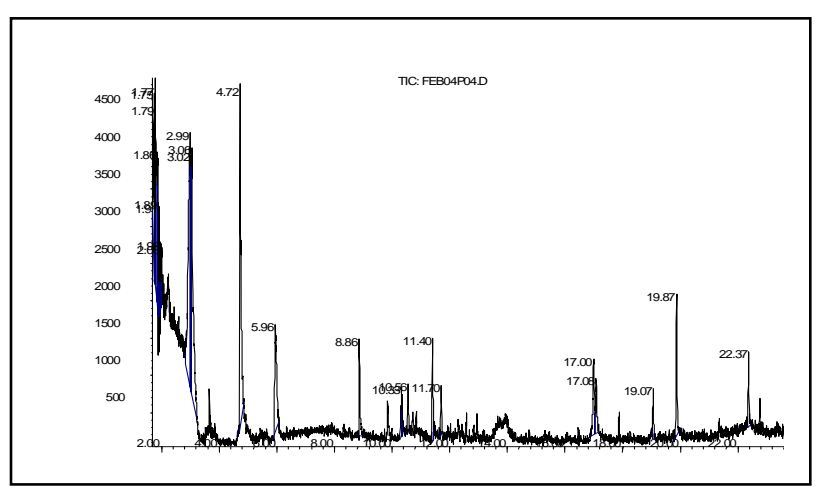

Fig. 7. Chromatogram of volatile compounds of a freshly prepared powdered semi-finished product from mushrooms containing $8 \%$ starch.

\section{Conclusion}

Taking into account the results of the study, we can conclude that the most rational is the sample, which consists of $8 \%$ starch to the mass of mushrooms boiled in their own juice, and the starch is introduced in dry form at a temperature of $45^{\circ} \mathrm{C}$.

Thus, the conditions for stabilization and preservation of the taste and aroma properties of natural mushrooms by using potato starch in the technology of powdered semi-finished products from mushrooms are scientifically justified. The sorbing effect of starch polysaccharides in the recipe composition of mushrooms-starch in the drying process has been proved. 


\section{References}

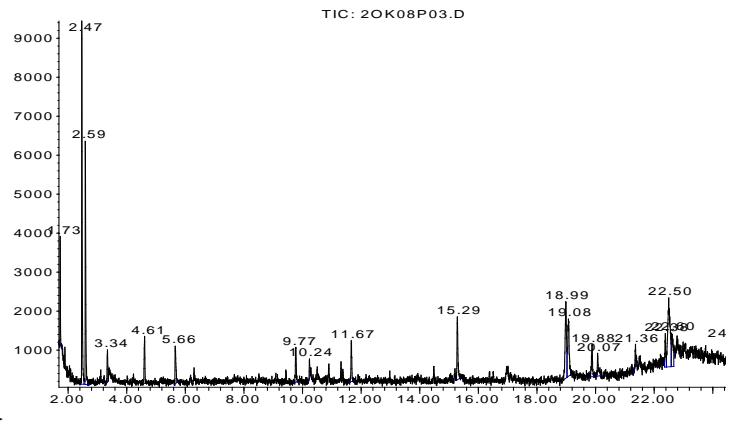

1. G.V. Semenov, Vacuum freeze drying.( Deli plus, Moscow, 2013)

2. V.A. Andreenkov, A. N. Polshkov, and T. A. Misharina, Food industry, 10, 63-65 (2001)

3. N. Cayot, C. Taisant, and A. Voilley, Journal of Agricultural and Food Chemistry, 46(8), 3201-3206 (1998)

4. M. A. Grishin, V. I. Atanasevich, Y. G. Semenov, Installation for drying food products: Reference book.(Agropromizdat, Moscow, 1989)

5. Chromatographic mass spectrophotometer.of firm "Agilent Technologies", Technical description and operating instructions (1995)

Fig. 8. Chromatogram of volatile compounds of a powdered semi-finished mushroom product that does not contain starch, after storage for 12 months

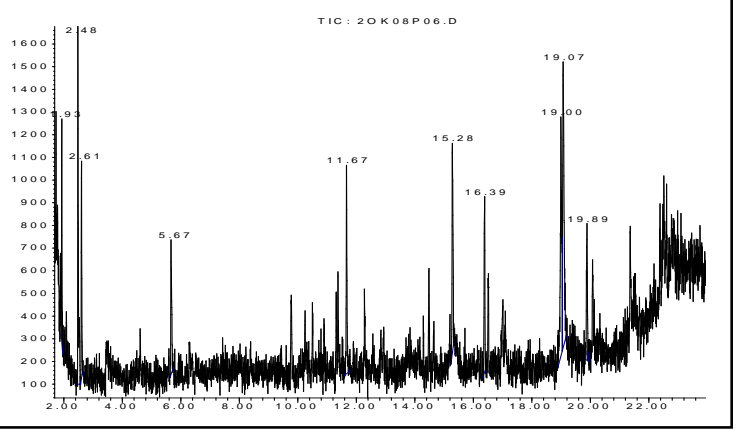

6. J. Korus, P. Tomasik, and C.Y. Lii, J Microencapsul, 20(1), 47-56 (2003)

7. D.J. Gallant, B. Bonchet, and P.M. Baldwin, Carbohydr. Polum, 32, 177-191 (1997)

8. J. Szymonska, F. Krok, and P. Tomasik, J. Biol. Macromol, 27, 307-314 (2000)

9. P. Tomasik, C.Y. Lii, and J. Korusa, Starch granules as microcapsules "Starch and starch-containing sources-structure, properties and new technologies in Collection of the 1 st Moscow international conference, 22 (2001)

10. C.G. Biliaderis, Food Technol, 46, 98-109 (1992)

11. r J. Vette and J. Rimoczi, Cryptog. Mycol, 10, 107117 (1981)

12. O. Burich and F. Berki, Drying of fruits and vegetables.( Food industry, Moscow, 1978)
Fig. 9. Chromatogram of volatile compounds of powdered semi-finished product from mushrooms containing $5 \%$ starch, after storage for 12 months

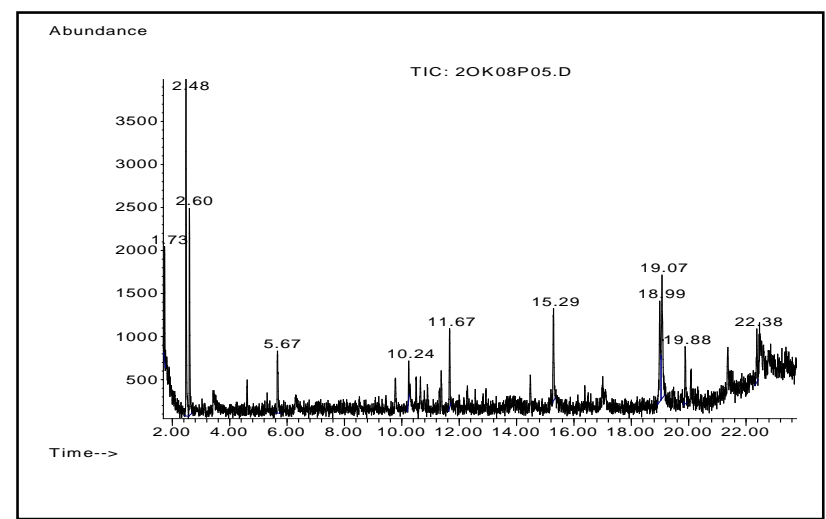

Fig. 10. Chromatogram of volatile compounds of powdered semi-finished product from mushrooms containing $5 \%$ starch, after storage for 12 months 